Article

\title{
DC Flashover Performance of Ice-Covered Composite Insulators with Parallel Air Gaps
}

\section{Jianlin Hu ${ }^{1, *}$, Xingliang Jiang ${ }^{1}$, Fanghui Yin ${ }^{2}$ and Zhijin Zhang ${ }^{1}$}

1 State Key Laboratory of Power Transmission Equipments \& System Security and New Technology, School of Electrical Engineering, Chongqing University, Chongqing 400030, China;

E-Mails: xljiang@cqu.eud.cn (X.J.); zhangzhijing@cqu.edu.cn (Z.Z.)

2 NSERC/Hydro-Quebec/UQAC Industrial Chair on Atmospheric Icing of Power Network Equipment (CIGELE) and Canada Research Chair on Engineering of Power Network Atmospheric Icing (INGIVRE), Université du Québec à Chicoutimi, Chicoutimi, QC G7H 2B1, Canada;

E-Mail: fanghui.yin1@uqac.ca

* Author to whom correspondence should be addressed; E-Mail: hujianlin@cqu.edu.cn; Tel.: +86-23-6511-1172 (ext. 8219); Fax: +86-23-6510-6818.

Academic Editor: Tariq Al-Shemmeri

Received: 16 March 2015 / Accepted: 22 May 2015 / Published: 28 May 2015

\begin{abstract}
DC flashover performance of ice-covered composite insulators with a parallel air gap (CI/PAG) is an important technical consideration when such insulators are used to isolate ground wires for the purpose of DC ice-melting. Tests on tension and suspension types of CI/PAG were thus carried out in the artificial climate chamber to investigate their DC icing flashover performance. The influences of parallel air gap, ice thickness, pollution severity and air pressure on DC negative $50 \%$ flashover voltage $\left(U_{50 \%}\right)$ of CI/PAG were investigated. Test results show that the parallel air gap affected both the discharge path and $U_{50 \%}$. With increasing ice thickness, $U_{50 \%}$ declined by up to $52 \%$; this effect was more evident when the breakdown occurred in the air gap. The pollution severity affected $U_{50 \%}$ only when the flashover happened along insulator surface. With a decrease of atmospheric pressure, $U_{50 \%}$ decreased. $U_{50 \%}$ and the ratio of air pressure were in a power function relationship with a positive characteristic exponent which was relevant to the discharge path.
\end{abstract}

Keywords: DC icing flashover; composite insulator; parallel air gap; low air pressure; outdoor insulation 


\section{Introduction}

Icing, an extreme weather condition, is a severe threat to the safe operation of overhead transmission lines around the world. The power lines in the US, Canada, Russia, France, Iceland, and Japan have suffered destructive snow and ice disasters during their history [1-7]. In China, icing accidents of transmission lines occur frequently due to miscellaneous macroclimatic, microtopographical and micrometeorological weather conditions. In particular in 2008, a severe ice storm struck Southern China, resulting in the collapse of 8381 transmission line towers (110 kV class and above) and accidents such as blackouts which caused huge economic losses [8].

DC ice-melting for conductors is one of the effective methods to prevent conductor fracture and tower collapse caused by icing on transmission lines [3]. In recent years, DC ice-melting techniques for overhead power transmission line conductors have well developed, and the State Grid Corporation of China and China Southern Power Grid Co., Ltd. have installed dozens of fixed and movable DC ice-melting devices, which have successfully implemented hundreds of DC ice-melting tasks for transmission line conductors [9-12]. However, ground wires cannot be directly de-iced with DC ice-melting method due to their intrinsic characteristics, such as tower-after-tower grounding, single-point grounding, multi-points grounding and low insulation level. If the icing on ground wires cannot be removed or melted, ground wires are liable to displacement, fracture, or excessive sag which can cause phase-to-ground discharge and finally outages of the transmission lines.

It is necessary to enhance the insulation of ground wires for the DC ice-melting purpose. Meanwhile, for the sake of lightning protection, ground wire insulators should be installed with a parallel air gap in which breakdown occurs first when they undergo lightning strike. During the DC ice-melting process, the ice-melting voltage, which determines the current and the length of ground wires in terms of ice-melting, is limited by the flashover voltage of ice-covered insulators and the breakdown voltage of parallel air gap. Therefore, it is important to select the optimal length of ground wire insulators and the distance of parallel air gap.

Up to now, research institutes have conducted numerous investigations on the icing flashover performance of insulators and have achieved a consensus on the effects of insulator length, ice thickness, conductivity of freezing water, pollution severity on insulator surface and air pressure on the flashover performance of ice-covered composite insulators [1,13-19]. However, there are no reported studies on the DC flashover performance of ice-covered insulators with parallel air gap.

The lack of related knowledge has motivated the present study which aims to investigate the icing performance of CI/PAG. The paper investigated two types of CI/PAGs, and studied their DC negative flashover performance under the conditions of various air gap distances, ice thicknesses, pollution severities, and atmospheric pressures in the artificial climate chamber. This research may pave the way for the ground-wire insulation design applied to ground wire DC ice-melting.

\section{Test Facilities, Samples, and Test Methods}

\subsection{Test Facilities}

The tests were carried out in the artificial climate chamber of State Key Laboratory of Power Transmission Equipment \& System Security and New Technology, College of Electrical Engineering, 
Chongqing University. The artificial climate chamber has a diameter of $7.8 \mathrm{~m}$ and a height of $11.6 \mathrm{~m}$. It mainly consists of a refrigeration system, a vacuum-pumping system, a spraying system, and a wind velocity regulating system. Air temperature in the artificial climate chamber is controlled by a proportional integral and differential system with a precision of about $\pm 0.5{ }^{\circ} \mathrm{C}$. Minimum temperature in the chamber can be adjusted to $-45 \pm 1{ }^{\circ} \mathrm{C}$. Air pressure in the chamber can be as low as $30 \mathrm{kPa}$, capable of simulating the atmospheric conditions at an altitude of $7000 \mathrm{~m}$. The spraying system consists of two rows of fog nozzles and mounted on an oscillating support parallel to the axis of the insulators at a distance of $3.5 \mathrm{~m}$. The spraying system is $3.36 \mathrm{~m}$ high and $0.43 \mathrm{~m}$ wide. The oscillating movement helps keep the mean liquid water content approximately constant along the vertical axis of the insulators, thus forming ice with a uniform thickness along the insulator string. A relatively uniform wind is obtained using a system of 10 fans placed in a tapering box with a diffusing honeycomb panel. Wind velocity in the chamber can be adjusted to 0 to $12 \mathrm{~m} / \mathrm{s}$.

The test voltage was supplied by $\pm 600 \mathrm{kV} / 0.5$ A cascade rectifying circuit controlled by the thyristor voltage-current feedback system. The technical parameters of DC test power supply are as follows: power supply $=\mathrm{AC} 10 \mathrm{kV}$, maximum output voltage $=600 \mathrm{kV}$, ripple factor of the test voltage for a $500 \mathrm{~mA}$ current with a resistive load $<3 \%$, relative voltage drop occurring during individual tests resulting in withstand $\leq 5 \%$, and relative voltage overshoot due to load-release caused by the extinction of electrical discharges on insulator surface $\leq 8 \%$. The test voltage was measured by ZGF-600 resistive potential divider with a precision of $0.5 \%$ (for more details see [19]).

\subsection{Test Samples}

This research investigated two types of CI/PAGs, namely FXBZW- $\pm 25 / 120 \mathrm{~B}$ and FXBZW- $\pm 25 / 120 \mathrm{C}$, which are typical composite insulators for ground wires of overhead power transmission lines. Parameters and structure diagram of the samples are listed in Table 1 and Figure 1, where $H$ is the insulator's structure height; $h_{1}$ is the insulation length; $h$ is the distance of parallel air gap and $L$ is the insulator's creepage distance.

Table 1. The parameters of two types of test samples.

\begin{tabular}{ccccccc}
\hline \multirow{2}{*}{ Sample } & \multirow{2}{*}{ Type } & $\begin{array}{c}\text { Structure height } \\
\boldsymbol{H}(\mathbf{m m})\end{array}$ & $\begin{array}{c}\text { Insulation length } \\
\boldsymbol{h}_{\mathbf{1}}(\mathbf{m m})\end{array}$ & Air gap distance & Creepage distance & \multicolumn{2}{c}{ Mounting } \\
& & $(\mathbf{m m})$ & $\boldsymbol{L}(\mathbf{m m})$ & type \\
\hline $\mathrm{A}$ & $\mathrm{FXBZW}- \pm 25 / 120 \mathrm{~B}$ & 600 & 339 & $20 \sim 120$ & 1100 & Tension \\
$\mathrm{B}$ & $\mathrm{FXBZW}- \pm 25 / 120 \mathrm{C}$ & 590 & 339 & $20 \sim 120$ & 1100 & Suspension \\
\hline
\end{tabular}

\subsection{Test Procedure and Methods}

The main procedures of the icing flashover experiment include: preparation of tested samples, artificial pollution, ice deposit, and flashover tests for ice-covered insulators. The details are presented in [19]. 


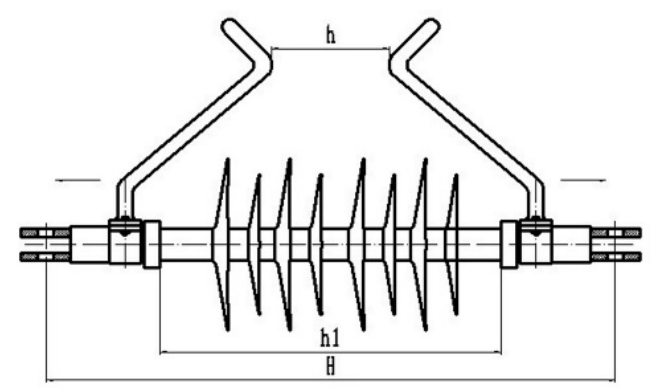

(a)
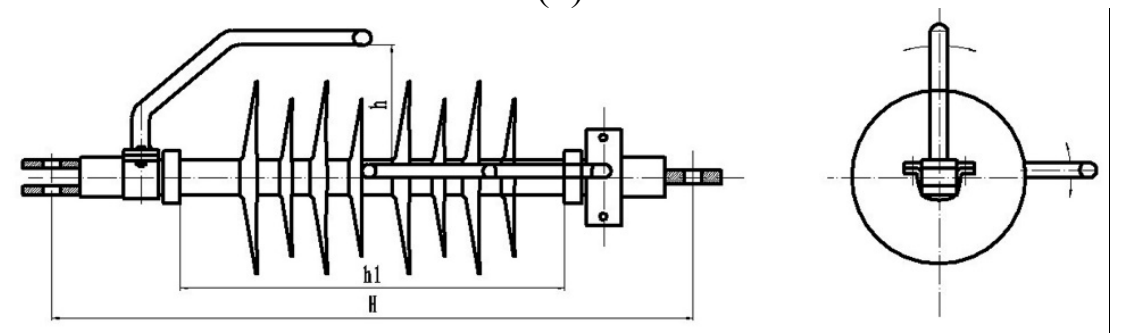

(b)

Figure 1. The structural graph of tested CI/PAG. (a) FXBZW- $\pm 25 / 120 B$; (b) FXBZW- $\pm 25 / 120 C$.

The ice deposit parameters are listed in Table 2. Under such conditions, the density of wet-grown ice formed on the composite insulators ranged from approximately 0.84 to $0.90 \mathrm{~g} / \mathrm{cm}^{3}$. It is the most dangerous type of ice known as wet-grown ice or glaze with the highest probability of flashover. The average ice thickness $(d)$ on a monitoring rotating cylinder was adopted as a parameter to represent the ice thickness on insulators. The cylinder had a diameter of $28 \mathrm{~mm}$ and rotated at $1 \mathrm{rpm}$. It was installed near the test samples within the water spraying zone.

Table 2. Experimental parameters of ice deposits.

\begin{tabular}{cccc}
\hline $\begin{array}{c}\text { Freezing water conductivity } \\
(\boldsymbol{\mu S} / \mathbf{c m})\left(\mathbf{2 0}{ }^{\circ} \mathbf{C}\right)\end{array}$ & $\begin{array}{c}\text { Freezing water flux } \\
\left(\mathbf{L} / \mathbf{h} \cdot \mathbf{m}^{\mathbf{2}}\right)\end{array}$ & $\begin{array}{c}\text { Air temperature } \\
\left({ }^{\circ} \mathbf{C}\right)\end{array}$ & $\begin{array}{c}\text { Wind velocity } \\
(\mathbf{m} / \mathbf{s})\end{array}$ \\
\hline 100 & $\sim 90$ & $-7 \sim-5$ & $\sim 3$ \\
\hline
\end{tabular}

The up-and-down method was chosen to obtain the $50 \%$ icing flashover voltage $\left(U_{50 \%}\right)$, and the detailed procedure is as follows: (a) Spraying was carried out until the desired ice thickness; (b) insulators were frozen for 15-20 min; (c) the cooling system was shut down; (d) the temperature in the chamber was increased by $2-3{ }^{\circ} \mathrm{C} / \mathrm{h}$; (e) the estimated flashover voltage was applied to the iced insulators when the ambient temperature in the artificial chamber reached the range from -1.0 to $0.5{ }^{\circ} \mathrm{C}$. After that, the voltage determined by the previous test was applied to the another sample. If there was withstand in the previous test, the next test voltage was increased by $\Delta U$. Otherwise, the next voltage was decreased by $\Delta U$. The voltage step $\Delta U$ was about $5 \%$ of the initial voltage. Voltage was applied to each sample once. The withstand was defined as no flashover for at least $30 \mathrm{~min}$. The first test that yields a result different from the preceding ones and the following tests are defined as "valid" tests. Under each condition, valid tests were carried out not less than 10 times. According to the test results, $U_{50 \%}$ and the standard deviation can be calculated by: 


$$
\left\{\begin{array}{l}
U_{50 \%}=\sum_{i=1}^{N} U(i) / N \\
\sigma=\sqrt{\sum_{i=1}^{N}\left(U(i)-U_{50 \%}\right)^{2} / N}
\end{array}\right.
$$

where $U(i)$ is the applied voltage of the $i$ th test in $\mathrm{kV} ; N$ is the total number of valid tests.

The previous research $[17,20,21]$ shows that the pollution and icing flashover voltages of insulators under negative DC voltage are lower than those under positive DC voltage. In addition, since the parallel air gap of the tested insulators is a symmetrical rod-rod configuration, the breakdown process under DC voltage is not obviously affected by polarity. Therefore, the DC negative voltage which is the worst case was selected in this study. External insulation design based on these test results will be more reliable due to the extra safety margin.

\section{Test Results and Analysis}

\subsection{Test Results}

In the experiment, the tested CI/PAGs were laid out according to the actual arrangement of transmission lines. Sample A was horizontally placed and the parallel air gap was in horizontaldirection with its metal fittings mounted vertically. Sample B was vertically placed and the parallel air gap was in horizontal direction.

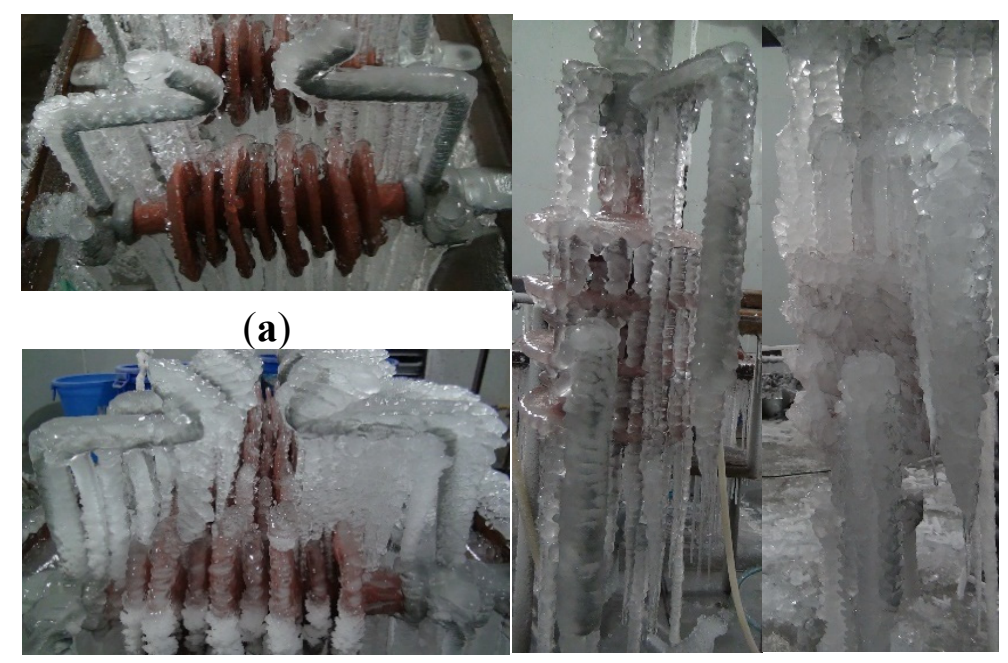

(b)

(c)

(d)

Figure 2. Icing states of two types of samples. (a) FXBZW- $\pm 25 / 120 \mathrm{~B}, h=80 \mathrm{~mm}$, $d=10 \mathrm{~mm}$; (b) FXBZW- $\pm 25 / 120 \mathrm{~B}, h=80 \mathrm{~mm}, d=20 \mathrm{~mm}$; (c) FXBZW- $\pm 25 / 120 \mathrm{C}$, $h=80 \mathrm{~mm}$; (d) FXBZW- $\pm 25 / 120 \mathrm{C}, h=80 \mathrm{~mm}, d=20 \mathrm{~mm}$.

To simulate the worst weather conditions, the parallel air gap was on the windward side during icing. The conditions of the tests are as follows: the pre-pollution salt deposit densities $(S D D)$ of the tested insulators before icing were 0.05 and $0.08 \mathrm{mg} / \mathrm{cm}^{2}$ respectively. The ratio of $S D D$ to non-soluble deposit density $(N S D D)$ was fixed at 1:6. The atmospheric pressure $P$ was fixed at $98.7 \mathrm{kPa}$. The ice thicknesses $d$ of the monitoring conductor were 10 and $20 \mathrm{~mm}$ respectively. The distances of parallel 
air gaps were 40,60, 80 and $100 \mathrm{~mm}$ respectively. Some pictures of tested samples are shown in Figure 2. The 50\% flashover voltages obtained under DC negative are shown in Tables 3 and 4.

Table 3. The test results of Sample A $(P=98.7 \mathrm{kPa})$.

\begin{tabular}{|c|c|c|c|c|c|}
\hline$h(\mathrm{~mm})$ & $d(\mathrm{~mm})$ & $S D D / N S D D\left(\mathrm{mg} / \mathrm{cm}^{2}\right)$ & $U_{50 \%}(\mathrm{kV})$ & Standard deviation $\sigma \%$ & Discharge path \\
\hline \multirow{4}{*}{40} & \multirow{2}{*}{10} & $0.05 / 0.30$ & 44.7 & 5.3 & Air gap breakdown \\
\hline & & $0.08 / 0.48$ & 43.7 & 6.1 & Air gap breakdown \\
\hline & \multirow{2}{*}{20} & $0.05 / 0.30$ & 34.5 & 5.7 & Air gap breakdown \\
\hline & & $0.08 / 0.48$ & 35.3 & 6.9 & Air gap breakdown \\
\hline \multirow{4}{*}{60} & \multirow{2}{*}{10} & $0.05 / 0.30$ & 57.6 & 4.8 & Air gap breakdown \\
\hline & & $0.08 / 0.48$ & 56.4 & 5.0 & Air gap breakdown \\
\hline & \multirow{2}{*}{20} & $0.05 / 0.30$ & 46.2 & 5.9 & Air gap breakdown \\
\hline & & $0.08 / 0.48$ & 45.6 & 6.3 & Air gap breakdown \\
\hline \multirow{4}{*}{80} & \multirow{2}{*}{10} & $0.05 / 0.30$ & 72.8 & 5.1 & Flashover on insulator \\
\hline & & $0.08 / 0.48$ & 63.4 & 5.9 & Flashover on insulator \\
\hline & \multirow{2}{*}{20} & $0.05 / 0.30$ & 51.7 & 4.4 & Air gap breakdown \\
\hline & & $0.08 / 0.48$ & 52.6 & 6.0 & Flashover on insulator \\
\hline \multirow{4}{*}{100} & \multirow{2}{*}{10} & $0.05 / 0.30$ & 71.3 & 4.4 & Flashover on insulator \\
\hline & & $0.08 / 0.48$ & 64.6 & 5.0 & Flashover on insulator \\
\hline & \multirow{2}{*}{20} & $0.05 / 0.30$ & 59.2 & 4.0 & Flashover on insulator \\
\hline & & $0.08 / 0.48$ & 53.8 & 6.9 & Flashover on insulator \\
\hline
\end{tabular}

Table 4. The test results of Sample B $(P=98.7 \mathrm{kPa})$.

\begin{tabular}{|c|c|c|c|c|c|}
\hline$h(\mathrm{~mm})$ & $d(\mathrm{~mm})$ & $S D D / N S D D\left(\mathrm{mg} / \mathrm{cm}^{2}\right)$ & $U_{50 \%}(\mathrm{kV})$ & Standard deviation $\sigma \%$ & Discharge path \\
\hline \multirow{4}{*}{40} & \multirow{2}{*}{10} & $0.05 / 0.30$ & 24.2 & 7.3 & Air gap breakdown \\
\hline & & $0.08 / 0.48$ & 22.9 & 8.3 & Air gap breakdown \\
\hline & \multirow{2}{*}{20} & $0.05 / 0.30$ & 13.2 & 9.7 & Air gap breakdown \\
\hline & & $0.08 / 0.48$ & 14.1 & 9.2 & Air gap breakdown \\
\hline \multirow{4}{*}{60} & \multirow{2}{*}{10} & $0.05 / 0.30$ & 39.8 & 5.8 & Air gap breakdown \\
\hline & & $0.08 / 0.48$ & 40.2 & 6.1 & Air gap breakdown \\
\hline & \multirow{2}{*}{20} & $0.05 / 0.30$ & 20.2 & 6.9 & Air gap breakdown \\
\hline & & $0.08 / 0.48$ & 18.2 & 7.2 & Air gap breakdown \\
\hline \multirow{4}{*}{80} & \multirow{2}{*}{10} & $0.05 / 0.30$ & 47.3 & 4.3 & Flashover on insulator \\
\hline & & $0.08 / 0.48$ & 43.3 & 5.9 & Flashover on insulator \\
\hline & \multirow{2}{*}{20} & $0.05 / 0.30$ & 35.5 & 5.8 & Air gap breakdown \\
\hline & & $0.08 / 0.48$ & 33.9 & 6.3 & Flashover on insulator \\
\hline \multirow{4}{*}{100} & \multirow{2}{*}{10} & $0.05 / 0.30$ & 46.9 & 5.5 & Flashover on insulator \\
\hline & & $0.08 / 0.48$ & 42.6 & 4.5 & Flashover on insulator \\
\hline & \multirow{2}{*}{20} & $0.05 / 0.30$ & 39.8 & 5.2 & Flashover on insulator \\
\hline & & $0.08 / 0.48$ & 35.2 & 4.5 & Flashover on insulator \\
\hline
\end{tabular}

In order to analyze the influences of high altitude and low air pressure on the icing flashover performance of $\mathrm{CI} / \mathrm{PAG}$, contrast tests were carried out on both types of CI/PAGs. Within this study, $S D D$ was $0.08 \mathrm{mg} / \mathrm{cm}^{2}$, air pressure was set at 89.8 and $79.5 \mathrm{kPa}$ which simulated altitudes of $1000 \mathrm{~m}$ and $2000 \mathrm{~m}$, respectively. The icing thickness was fixed at $20 \mathrm{~mm}$. The test results are shown in Table 5. 
Table 5. The test results under low air pressure conditions $\left(S D D=0.08 \mathrm{mg} / \mathrm{cm}^{2}, d=20 \mathrm{~mm}\right)$.

\begin{tabular}{|c|c|c|c|c|c|}
\hline Sample & $h(\mathrm{~mm})$ & $P(\mathrm{kPa})$ & $U_{50 \%}(\mathbf{k V})$ & Standard deviation $\sigma \%$ & Discharge path \\
\hline \multirow{4}{*}{ A } & \multirow{2}{*}{60} & 89.8 & 41.5 & 4.9 & Air gap breakdown \\
\hline & & 79.5 & 38.4 & 6.7 & Air gap breakdown \\
\hline & \multirow{2}{*}{80} & 89.8 & 49.4 & 5.9 & Flashover on insulator \\
\hline & & 79.5 & 46.5 & 6.1 & Flashover on insulator \\
\hline \multirow{4}{*}{ B } & \multirow{2}{*}{60} & 89.8 & 16.7 & 7.9 & Air gap breakdown \\
\hline & & 79.5 & 15.4 & 8.2 & Air gap breakdown \\
\hline & \multirow{2}{*}{80} & 89.8 & 31.8 & 6.7 & Flashover on insulator \\
\hline & & 79.5 & 30.1 & 6.2 & Flashover on insulator \\
\hline
\end{tabular}

\subsection{Influence of Parallel Air Gap}

As shown in Tables 3 and 4, the influence of parallel air gap on DC flashover performance of iced-covered CI/PAG mainly includes two aspects: the discharge path in the flashover process and the $50 \%$ flashover voltage.

In the tests, when the distances of parallel air gap were set at 40 and $60 \mathrm{~mm}$, all the breakdowns occurred in the parallel air gaps. The discharge paths are shown in Figures $3 a, b$ and $4 a, b$. With the same ice thickness and $S D D$, the $50 \%$ flashover voltage increased with an increase of parallel gap distance. In such a case, $S D D$ had a negligible impact on $50 \%$ flashover voltage.

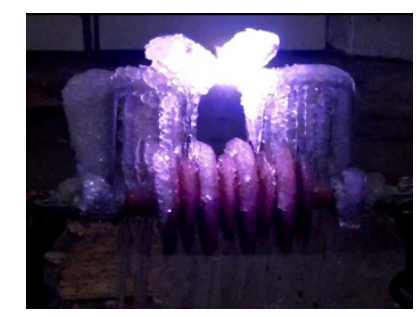

(a)

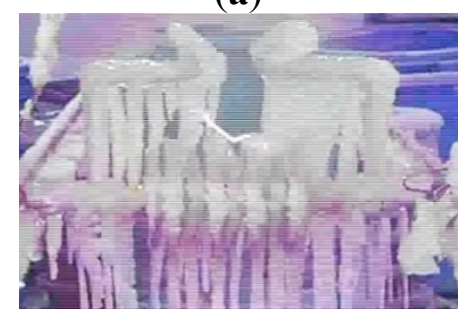

(d)

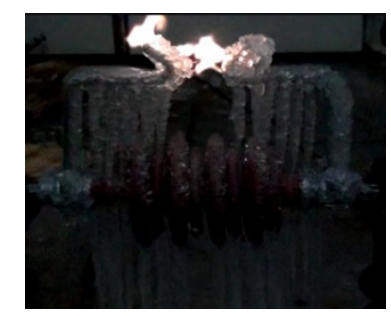

(b)

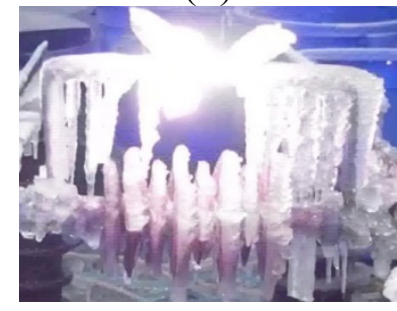

(e)

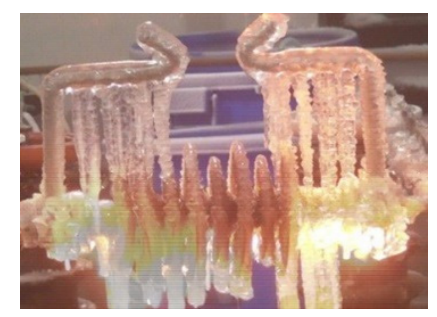

(c)

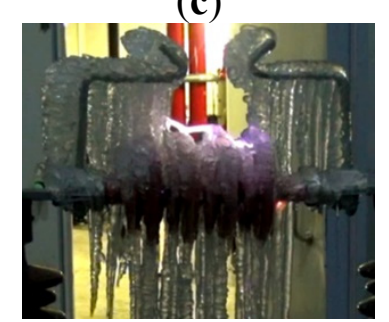

(f)

Figure 3. The different discharge paths of Sample A. (a) $h=40 \mathrm{~mm}$, air gap breakdown; (b) $h=60 \mathrm{~mm}$, air gap breakdown; (c) $h=80 \mathrm{~mm}, d=10 \mathrm{~mm}$, flashover on insulator; (d) $h=80 \mathrm{~mm}, d=20 \mathrm{~mm}$, flashover on insulator; (e) $h=80 \mathrm{~mm}, d=20 \mathrm{~mm}$, air gap breakdown; (f) $h=100 \mathrm{~mm}$, flashover on insulator.

For example, the $U_{50 \%}$ of Sample A was $44.7 \mathrm{kV}$, with $h$ of $40 \mathrm{~mm}, d$ of $10 \mathrm{~mm}$ and $S D D$ of $0.05 \mathrm{mg} / \mathrm{cm}^{2}$. However, when $S D D$ was increased to $0.08 \mathrm{mg} / \mathrm{cm}^{2}$, with all the other parameters remaining the same, the $U_{50 \%}$ decreased to $43.7 \mathrm{kV}$ with a difference of only $1 \mathrm{kV}$. The $U_{50 \%}$ of Sample B was $24.2 \mathrm{kV}$ with $h$ of $40 \mathrm{~mm}, d$ of $10 \mathrm{~mm}$ and $S D D$ of $0.05 \mathrm{mg} / \mathrm{cm}^{2}$. When $S D D$ was 
increased to $0.08 \mathrm{mg} / \mathrm{cm}^{2}$, the $U_{50 \%}$ was reduced to $22.9 \mathrm{kV}$, with a difference of $1.3 \mathrm{kV}$. These differences are within the experimental tolerances.

When the distances of parallel air gap were 80 and $100 \mathrm{~mm}$, the icing flashover of these two types of CI/PAGs mainly occurred along the iced insulators, as shown in Figures $3 \mathrm{c}-\mathrm{f}$ and $4 \mathrm{c}, \mathrm{e}, \mathrm{f}$. There was an exception that with $h$ of $80 \mathrm{~mm}, d$ of $20 \mathrm{~mm}$ and $S D D$ of $0.05 \mathrm{mg} / \mathrm{cm}^{2}$, the breakdown occurred in the parallel air gap, as shown in Figure 4d. When the flashover took place along the surface of iced insulators, the distance of parallel air gap had a negligible impact on $U_{50 \%}$. For example, the $U_{50 \%}$ of Sample A was $72.8 \mathrm{kV}$ with $h$ of $80 \mathrm{~mm}, d$ of $10 \mathrm{~mm}$ and $S D D$ of $0.05 \mathrm{mg} / \mathrm{cm}^{2}$. However, when $h$ was increased to $100 \mathrm{~mm}$, the $U_{50 \%}$ was reduced to $71.3 \mathrm{kV}$ with a difference of $1.5 \mathrm{kV}$; The $U_{50 \%}$ of Sample B was $47.3 \mathrm{kV}$ with $h$ of $80 \mathrm{~mm}, d$ of $10 \mathrm{~mm}$ and $S D D$ of $0.05 \mathrm{mg} / \mathrm{cm}^{2}$. When $h$ was increased to $100 \mathrm{~mm}$, the $U_{50 \%}$ was $46.9 \mathrm{kV}$, resulting in a difference of only $0.4 \mathrm{kV}$.

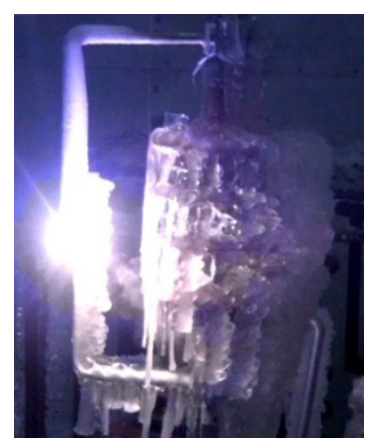

(a)

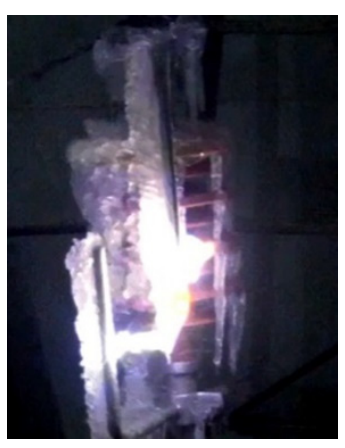

(b)

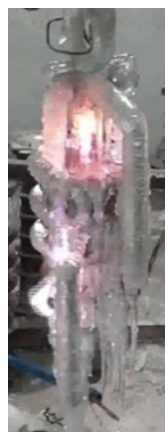

(c)

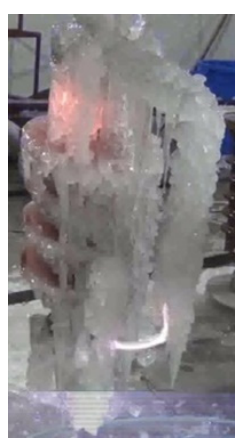

(d)

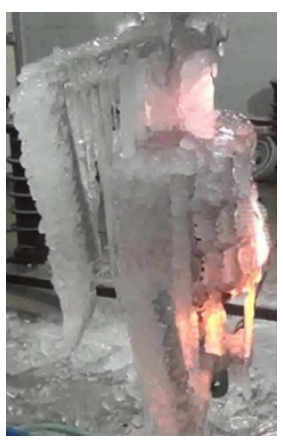

(e)

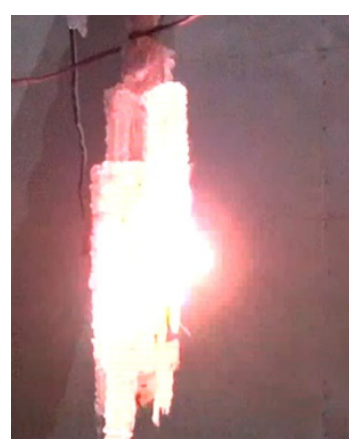

(f)

Figure 4. The different discharge paths of Sample B. (a) $h=40 \mathrm{~mm}$, air gap breakdown; (b) $h=60 \mathrm{~mm}$, air gap breakdown; (c) $h=80 \mathrm{~mm}, d=10 \mathrm{~mm}$, flashover on insulator; (d) $h=80 \mathrm{~mm}, d=20 \mathrm{~mm}$, air gap breakdown; (e) $h=80 \mathrm{~mm}, d=20 \mathrm{~mm}$, flashover on insulator; (f) $h=100 \mathrm{~mm}$, flashover on insulator.

For further analysis of the influence of parallel air gap on icing flashover performance of CI/PAG, this study evaluated the breakdown performance of clean insulators with different parallel air gaps or without parallel air gap under DC negative voltage. DC breakdown tests on clean insulators were carried out by raising the voltage until breakdown. The average value of five repeated test results was

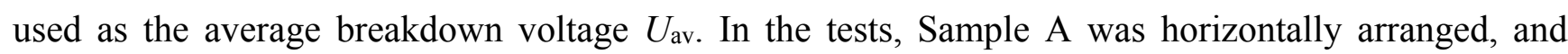
Sample B was vertically arranged. The environmental conditions were set with ambient temperature of $23{ }^{\circ} \mathrm{C}$, air pressure of $98.7 \mathrm{kPa}$, and relative humidity of $78 \%$. The test results are shown in Table 6 . The flashover tests of ice-covered composite insulators without parallel air gap were carried out by the test method mentioned in Section 2 to obtain the $U_{50 \%}$. In the tests, the tension insulators were horizontally arranged, and the suspension insulators were vertically arranged. The icing conditions were the same with those in Table 2 . The results of $U_{50 \%}$ are shown in Table 7.

The existence of a parallel air gap provides an additional discharge path for insulators. Under the condition of multiple potential discharge paths, the discharge will start along the path with least resistance. Based on the comparative analysis of the test results in Tables 3,4,6 and 7, it is found that: (1) for clean insulators without ice, the breakdown voltage of air gap was lower than the DC flashover voltage of insulators when the parallel air gap spacing was between 20-120 mm. As a result, all of the 
breakdowns took place at the parallel air gap; (2) after the insulators were iced, the metal fittings of parallel gap were also covered with ice as shown in Figure 2. The gap consists of two parts: ice layer and air gap between ice layers. Since the electrical conductivity of the ice layer is much higher than that of the air [20], the breakdown voltage of parallel gap is mainly determined by the distance of air gap between ice layers. In the tests, the distance of the air gap between ice layers of the parallel gap was measured every time ice accreted. Take the Sample A for example, with $h=40 \mathrm{~mm}$ and $d=20 \mathrm{~mm}$, the average distance of the remaining air gap was about $14 \mathrm{~mm}$. The greatly shortened air gap distance led to the decrease of breakdown voltage which was lower than the flashover voltage of $55.8 \mathrm{kV}$ for iced insulator without parallel air gap, and resulted in the breakdown in the gap afterward. When $h=100 \mathrm{~mm}$ and $d=20 \mathrm{~mm}$, the average value of the remaining air gap was about $72 \mathrm{~mm}$. The breakdown voltage was higher than the flashover voltage of $55.8 \mathrm{kV}$ for iced insulator without parallel air gap. As a result, the flashover took place along the surface of sample insulators.

Table 6. The test results $U_{\text {av }}$ of clean CI/PAG.

\begin{tabular}{cccc}
\hline Sample & $\boldsymbol{h}(\mathbf{m m})$ & $\boldsymbol{U}_{\text {av }}(\mathbf{k V})$ & Discharge path \\
\hline \multirow{4}{*}{ A } & 20 & 45.3 & Air gap breakdown \\
& 40 & 63.6 & Air gap breakdown \\
& 60 & 76.2 & Air gap breakdown \\
& 80 & 80.8 & Air gap breakdown \\
& 100 & 92.0 & Air gap breakdown \\
120 & 99.4 & Air gap breakdown \\
\hline \multirow{3}{*}{$\mathrm{C}$} & 20 & 35.1 & Air gap breakdown \\
& 40 & 49.9 & Air gap breakdown \\
& 60 & 59.7 & Air gap breakdown \\
& 80 & 66.8 & Air gap breakdown \\
& 100 & 74.4 & Air gap breakdown \\
& 120 & 83.2 & Air gap breakdown \\
\hline
\end{tabular}

Table 7. The 50\% DC flashover voltages of ice-covered composite insulators without parallel air gap.

\begin{tabular}{|c|c|c|c|c|}
\hline Sample & $d(\mathrm{~mm})$ & $S D D / N S D D\left(\mathrm{mg} / \mathrm{cm}^{2}\right)$ & $U_{50 \%}(\mathrm{kV})$ & Standard deviations $(\sigma \%)$ \\
\hline \multirow{4}{*}{ A } & \multirow{2}{*}{10} & $0.05 / 0.30$ & 75.1 & 3.5 \\
\hline & & $0.08 / 0.48$ & 66.2 & 4.9 \\
\hline & \multirow{2}{*}{20} & $0.05 / 0.30$ & 62.6 & 4.8 \\
\hline & & $0.08 / 0.48$ & 55.8 & 4.4 \\
\hline \multirow{4}{*}{$\mathrm{B}$} & \multirow{2}{*}{10} & $0.05 / 0.30$ & 49.4 & 5.1 \\
\hline & & $0.08 / 0.48$ & 45.9 & 4.8 \\
\hline & \multirow{2}{*}{20} & $0.05 / 0.30$ & 42.8 & 5.9 \\
\hline & & $0.08 / 0.48$ & 38.3 & 6.0 \\
\hline
\end{tabular}

According to the analysis above, the distance of the parallel gap influences the icing discharge path. When the gap distance was short, for example, less than $60 \mathrm{~mm}$ in the tests for both types of CI/PAGs, the discharge took place at the parallel gap. The flashover voltage is determined by air gap distances and ice thickness. 
In addition, test results in Tables 3,4 and 7 show that even the flashover took place along the insulator surface, and the CI/PAG had a lower 50\% flashover voltage compared with CI without parallel gap. Take Sample A as an example, when $h=100 \mathrm{~mm}, d=20 \mathrm{~mm}$ and $S D D=0.05 \mathrm{mg} / \mathrm{cm}^{2}$, the $U_{50 \%}$ of Sample A CI/PAG was $59.2 \mathrm{kV}$ and the $U_{50 \%}$ of Sample A composite insulator without parallel gap was $62.6 \mathrm{kV}$. The former is $5.4 \%$ lower than the latter. For Sample B, when $h=100 \mathrm{~mm}$, $d=20 \mathrm{~mm}$ and $S D D=0.05 \mathrm{mg} / \mathrm{cm}^{2}$, the $U_{50 \%}$ of Sample B CI/PAG was $39.8 \mathrm{kV}$ and the $U_{50 \%}$ of Sample B composite insulator without parallel air gap was $42.8 \mathrm{kV}$. The former is $7.0 \%$ lower than the latter. It is observed that the main reason for the decrease of the $50 \%$ flashover voltage of ice-covered CI/PAGs is that the metal fittings change the ice morphology of the insulators. As shown in Figure 2, the downward development of the icicles of the horizontal parallel metal fittings of tension insulators make the insulator sheds more likely to be bridged by icicles; the icicles on the parallel metal fittings of the suspension insulator bridge some sheds and decrease the flashover voltage. In conclusion, as for $\mathrm{CI} / \mathrm{PAG}$, when the gap is relatively large, flashover happens along the iced insulator's surface. Since the influence of parallel metal fittings on $U_{50 \%}$ cannot be ignored, the ordinary iced insulator's $50 \%$ voltage gradient cannot be used for reference in terms of the configuration design of CI/PAG.

\subsection{Influence of Ice Thickness on $U_{50 \%}$}

The available research results show that the flashover voltages of ordinary insulators decrease with the increase of the ice thickness $d$ and the $U_{50 \%}$ can be expressed as a power function of $d$ with a negative characteristic exponent $[1,13,18,19]$. The test results in this study also reveal that with an increased ice thickness $d$, the $U_{50 \% \mathrm{~s}}$ of iced CI/PAGs decreases gradually. However, due to the influence of parallel air gap on the discharge path, the influence of ice thickness on $U_{50 \%}$ is different when breakdown happens in the parallel air gap or along the insulator surface. When the parallel air gap is relatively short, the breakdown occurs in the parallel air gap. As icing reduces the remaining air gap distance of the parallel air gap, the ice thickness has a significant influence on the air gap breakdown voltage. For example: for Sample A with $h$ of $40 \mathrm{~mm}$, the average flashover voltage $U_{\text {av }}$ was $63.6 \mathrm{kV}$ without icing; for $S D D=0.05 \mathrm{mg} / \mathrm{cm}^{2}$ and $d=10 \mathrm{~mm}$, the $U_{50 \%}$ was $44.7 \mathrm{kV}$, whereas the $U_{50} \%$ was only $34.5 \mathrm{kV}$ when breakdown occurred in parallel air gap with a $d$ of $20 \mathrm{~mm}$. Compared with sample without icing, $U_{50 \% \mathrm{~s}}$ of samples with $d$ of 10 and $20 \mathrm{~mm}$ declined by $29.7 \%$ and $45.8 \%$ respectively. For Sample B with $h$ of $40 \mathrm{~mm}$, the average flashover voltage $U_{\text {av }}$ was $49.9 \mathrm{kV}$ without icing. For $S D D=0.05 \mathrm{mg} / \mathrm{cm}^{2}$ and $d=10 \mathrm{~mm}$, the $U_{50 \%}$ was $24.2 \mathrm{kV}$; when breakdown happened at the parallel air gap with $d$ of $20 \mathrm{~mm}$, the $U_{50} \%$ was only $13.2 \mathrm{kV}$. Compared with sample without icing, $U_{50 \%}$ of samples with $d$ of 10 and $20 \mathrm{~mm}$ declined by $51.5 \%$ and $73.6 \%$ respectively. Based on the above analysis, the ice thickness exhibits more effects on DC negative flashover voltage of Sample B than on that of Sample A. When the parallel air gap distance is relatively large and flashover occurs along the insulator surface, the influence of ice thickness $d$ on $U_{50 \%}$ of CI/PAG is the same as that of ordinary ice-covered composite insulators [17-20]. For Sample A with $h$ of $100 \mathrm{~mm}$ and SDD of $0.05 \mathrm{mg} / \mathrm{cm}^{2}$, when $d=10 \mathrm{~mm}$, the $U_{50 \%}$ was $71.3 \mathrm{kV}$; when $d=20 \mathrm{~mm}$, the $U_{50 \%}$ was $59.2 \mathrm{kV}$, with the latter dropping by $16.7 \%$. For Sample B with $h$ of $100 \mathrm{~mm}$ and $S D D$ of $0.05 \mathrm{mg} / \mathrm{cm}^{2}$, when $d=10 \mathrm{~mm}$, the $U_{50 \%}$ was $46.9 \mathrm{kV}$; when $d=20 \mathrm{~mm}$, the $U_{50 \%}$ was $39.8 \mathrm{kV}$, with the latter dropping by $15.1 \%$. 
Since only two ice thicknesses were tested in this study, it is insufficient to obtain the characteristic exponent of ice thickness and more research is still needed in the future.

\subsection{Influence of SDD on $U_{50 \%}$}

The pre-pollution severity of iced insulators is a significant factor which influences the flashover performance of ice-covered insulators. For ordinary insulators, with the increase of contamination parameter $S D D, U_{50 \%}$ decreases accordingly in a power function $[18,19]$. The test results in Tables 3 and 4 present that when air gap breakdown occurs on the ice-covered CI/PAG, there are some deviations as to the $U_{50 \%}$ under different $S D D s$, but such differences are small and within the experimental tolerances. Thus it can be concluded that $U_{50 \%}$ is not affected by $S D D$ when breakdown occurs in the parallel air gap. However, when the flashover occurs along the surface of ice-covered insulator, $U_{50 \%}$ decreases with an increase of $S D D$. For example, for Sample A with $h$ of $100 \mathrm{~mm}$ and $d$ of $10 \mathrm{~mm}$, when $S D D$ was $0.05 \mathrm{mg} / \mathrm{cm}^{2}$, the $U_{50 \%}$ was $71.3 \mathrm{kV}$; when $S D D$ was increased to $0.08 \mathrm{mg} / \mathrm{cm}^{2}$, the $U_{50 \%}$ was $64.6 \mathrm{kV}$ with an decrease of $9.3 \%$; for Sample B with $h$ of $100 \mathrm{~mm}$ and $d$ of $10 \mathrm{~mm}$, when $S D D$ was $0.05 \mathrm{mg} / \mathrm{cm}^{2}$, the $U_{50 \%}$ was $46.9 \mathrm{kV}$; when $S D D$ was increased to $0.08 \mathrm{mg} / \mathrm{cm}^{2}$ the $U_{50 \%}$ was $42.6 \mathrm{kV}$, with the latter decreasing by $9.2 \%$, so, when the discharge path is along the insulator surface, the influence of $S D D$ on $U_{50 \%}$ of ice-covered CI/PAGs is consistent with that of ordinary ice-covered composite insulators [18,19].

\subsection{Influence of $P$ on $U_{50 \%}$}

The previous research results show that with an increase of altitude and a decrease of air pressure, both $50 \%$ breakdown voltage of air gap and $50 \%$ flashover voltage of polluted or ice-covered insulator decrease. There is a nonlinear relationship between the $50 \%$ discharge voltage $U_{50 \%}$ and air pressure $P$, shown as follows [18-20]:

$$
U_{50 \%}=U_{0} \times\left(P / P_{0}\right)^{n}
$$

where $U_{50 \%}$ and $U_{0}$, in $\mathrm{kV}$, are the $50 \%$ breakdown voltage of air gap or flashover voltage of the insulator under air pressure $P$ and $P_{0}$ respectively. $P_{0}$ is the standard atmospheric pressure with a value of $101.3 \mathrm{kPa} ; n$ is a characteristic exponent representing the influence of air pressure.

Fit the corresponding test results of Tables 3-5 according to Equation (2), the fitted curves obtained are shown in Figure 5, the corresponding $U, n$ and the correlation coefficients $R^{2}$ are shown in Table 8. Based on Figure 5 and Table 8, the following can be concluded:

(1) The $U_{50 \% \mathrm{~s}}$ of two types of ice-covered CI/PAGs decrease with the decrease of air pressure, no matter whether the discharge is located in parallel air gap or along ice-covered insulator surface. $U_{50 \%}$ and ratio of air pressure $\left(P / P_{0}\right)$ are in a power function relationship with a positive characteristic exponent.

(2) The characteristic exponent $n$ of pressure influence is related to the discharge path. For the two types of CI/PAGs, when the parallel air gap distance was $60 \mathrm{~mm}$ in which condition the breakdown occurred in the parallel gap, the characteristic exponents $n$ were 0.787 and 0.767 respectively. When the parallel gap distance was $80 \mathrm{~mm}$ (namely, the flashover occurs on ice-covered insulator surface), the characteristic exponents $n$ were 0.566 and 0.545 respectively. The $n$ of parallel gap breakdown is, 
therefore, larger than that of flashover on insulators, which indicates that the air pressure has bigger influence on $U_{50 \%}$ of parallel gap breakdown than that of flashover along the insulator.

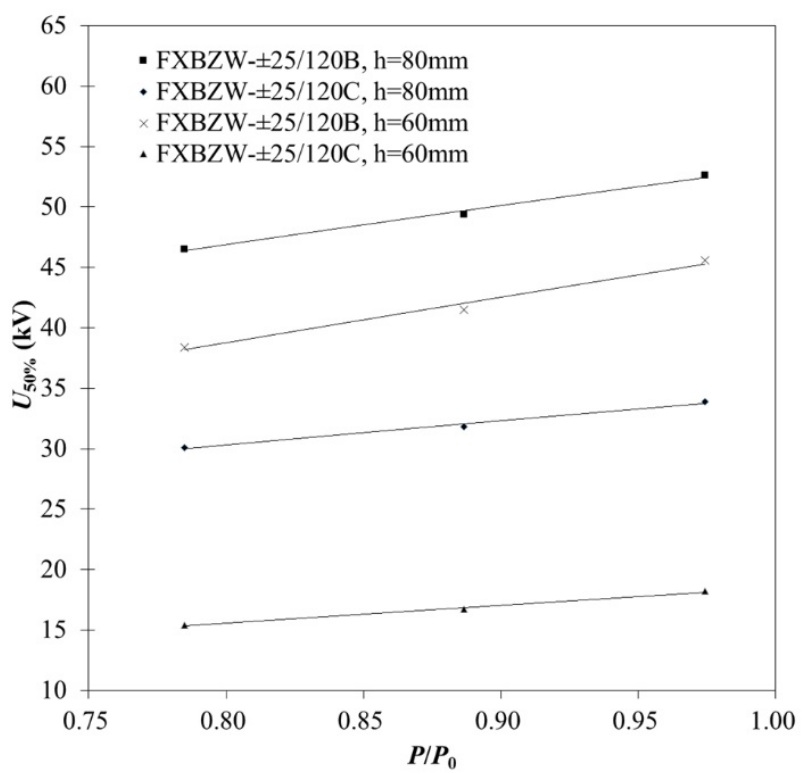

Figure 5. The relationship curves between the $U_{50 \%}$ and $P / P_{0}$.

Table 8. Fitting Values of $U_{0}, n$, and $R^{2}$ According to the Test Results in Tables $3-5$ with Equation (2).

\begin{tabular}{ccccc}
\hline \multirow{2}{*}{ Sample } & \multirow{2}{*}{$\boldsymbol{h}(\mathbf{m m})$} & \multicolumn{3}{c}{ Fitting values } \\
\cline { 3 - 5 } & 60 & $\boldsymbol{U}_{\mathbf{0}}(\mathbf{k V})$ & $\boldsymbol{n}$ & $\boldsymbol{R}^{\mathbf{2}}$ \\
\hline \multirow{2}{*}{$\mathrm{A}$} & 80 & 46.2 & 0.787 & 0.984 \\
& 60 & 53.2 & 0.566 & 0.993 \\
\hline \multirow{2}{*}{$\mathrm{B}$} & 80 & 18.5 & 0.767 & 0.992 \\
& 34.2 & 0.545 & 0.987 \\
\hline
\end{tabular}

\subsection{Icing Flashover Voltage Gradients}

Insulator flashover voltage gradient is a crucial parameter for the insulation design. According to the test results in Tables 3 and 4, for tension and suspension CI/PAGs with $h$ of 40 or $60 \mathrm{~mm}$ and $d$ of 10 or $20 \mathrm{~mm}$, all breakdowns happened at parallel gap and $U_{50 \%}$ were mainly determined by the distance of parallel gaps. When $h$ was 80 or $100 \mathrm{~mm}$ under the above two ice thicknesses, the discharge all occurred with flashover on insulators except the breakdown at the parallel gap with $h$ of $80 \mathrm{~mm}, d$ of $20 \mathrm{~mm}$ and $S D D$ of $0.05 \mathrm{mg} / \mathrm{cm}^{2}$. Therefore, the flashover voltage gradients for ice-covered insulators are analyzed in two situations, namely the breakdown in parallel gap and flashover on insulator.

\subsubsection{Voltage Gradients under the Condition of Air Gap Breakdown}

When the breakdown happens in parallel air gap, the breakdown voltage is mainly determined by the gap distance and the ice thickness. Then the flashover voltage gradient $E_{\mathrm{g}}$ of the ice-covered $\mathrm{CI} / \mathrm{PAG}$ is presented as: 


$$
E_{\mathrm{g}}=U_{50 \%} / h
$$

where $E_{\mathrm{g}}$ is the $50 \%$ flashover voltage gradient of ice-covered CI/PAG under the condition of breakdown in parallel gap, in $\mathrm{kV} / \mathrm{mm} ; U_{50 \%}$ is the corresponding $50 \%$ flashover voltage obtained from the tests, in $\mathrm{kV}$; $h$ is the distance of parallel air gap, in mm. According to Equation (3) and test results in Tables 3 and 4, the flashover voltage gradients $E_{\mathrm{g}}$ of the iced CI/PAG are calculated in Table 9.

Table 9. Flashover voltage gradients $E_{\mathrm{g}}$ of the ice-covered CI/PAG (air gap breakdown).

\begin{tabular}{|c|c|c|c|c|}
\hline Sample & $h(\mathbf{m m})$ & $d(\mathbf{m m})$ & $S D D / N S D D\left(\mathrm{mg} / \mathrm{cm}^{2}\right)$ & $E_{\mathrm{g}}(\mathrm{kV} / \mathrm{mm})$ \\
\hline \multirow{8}{*}{ A } & \multirow{4}{*}{40} & \multirow{2}{*}{10} & $0.05 / 0.30$ & 1.118 \\
\hline & & & $0.08 / 0.48$ & 1.093 \\
\hline & & \multirow{2}{*}{20} & $0.05 / 0.30$ & 0.863 \\
\hline & & & $0.08 / 0.48$ & 0.883 \\
\hline & \multirow{4}{*}{60} & \multirow{2}{*}{10} & $0.05 / 0.30$ & 0.960 \\
\hline & & & $0.08 / 0.48$ & 0.940 \\
\hline & & \multirow{2}{*}{20} & $0.05 / 0.30$ & 0.770 \\
\hline & & & $0.08 / 0.48$ & 0.760 \\
\hline \multirow{8}{*}{ B } & \multirow{4}{*}{40} & \multirow{2}{*}{10} & $0.05 / 0.30$ & 0.605 \\
\hline & & & $0.08 / 0.48$ & 0.573 \\
\hline & & \multirow{2}{*}{20} & $0.05 / 0.30$ & 0.330 \\
\hline & & & $0.08 / 0.48$ & 0.353 \\
\hline & \multirow{4}{*}{60} & \multirow{2}{*}{10} & $0.05 / 0.30$ & 0.663 \\
\hline & & & $0.08 / 0.48$ & 0.670 \\
\hline & & \multirow{2}{*}{20} & $0.05 / 0.30$ & 0.337 \\
\hline & & & $0.08 / 0.48$ & 0.303 \\
\hline
\end{tabular}

Based on Table 9, the following can be concluded:

(1) Under the condition of breakdown in parallel air gap, the flashover voltage gradient $E_{\mathrm{g}}$ is mainly determined by the ice thickness and is irrelevant to the pollution severity $S D D$.

(2) For Sample A, parallel air gap distance affects $E_{\mathrm{g}}$ to a certain extent under the same contamination condition. Take the contamination condition of $S D D=0.05 \mathrm{mg} / \mathrm{cm}^{2}$ for example, when the parallel air gap spacing $h$ was 40 and $60 \mathrm{~mm}, E_{\mathrm{g}}$ was 1.118 and $0.960 \mathrm{kV} / \mathrm{mm}$ respectively with a difference of 14.1\%; for Sample B, the gap distance $h$ has less influence on $E_{\mathrm{g}}$ under the same condition. In the case of $S D D=0.05 \mathrm{mg} / \mathrm{cm}^{2}$ and with $h$ of 40 and $60 \mathrm{~mm}, E_{\mathrm{g}}$ was 0.605 and $0.663 \mathrm{kV} / \mathrm{mm}$ respectively and the difference was $9.6 \%$. The main reason for the influence of gap distance on $E_{\mathrm{g}}$ may be the nonlinear growth of ice in the parallel air gap.

(3) The $E_{\mathrm{g}}$ is influenced significantly by the ice thickness $d$ and the $E_{\mathrm{g}}$ of Sample B is more affected by $d$ than that of Sample A. For Sample A with $h$ of $40 \mathrm{~mm}$, the $E_{\mathrm{g}}$ decreased by $21.1 \%$ with an increase of $d$ from 10 to $20 \mathrm{~mm}$; for Sample B with $h$ of $40 \mathrm{~mm}$, when $d$ increased from 10 to $20 \mathrm{~mm}$, the $E_{\mathrm{g}}$ declined by $42 \%$.

(4) The $E_{\mathrm{g}}$ of Sample B is significantly lower than that of Sample A under the same conditions, which can be explained from two aspects: First, the different metal fitting types lead to different electric-field distributions of air gap, and for Sample A, a relatively uniform electric field increases the 
breakdown voltage of tension insulator; Second, there exist different icing patterns for the two kinds of $\mathrm{CI} / \mathrm{PAGs}$ due to their different metal fittings and layout types.

\subsubsection{Voltage Gradients under the Condition of Flashover on Insulator}

When it comes to flashover along the insulator surface, $U_{50 \%}$ is mainly determined by insulation length, ice thickness and contamination severity. The flashover voltage gradient $E_{50 \%}$ can be calculated by the following equation:

$$
E_{50 \%}=U_{50 \%} / h_{1}
$$

where $E_{50 \%}$ is the $50 \%$ flashover voltage gradient of ice-covered $\mathrm{CI} / \mathrm{PAG}$ when flashover occurs along the surface of insulator, in $\mathrm{kV} / \mathrm{cm} ; U_{50 \%}$ is the $50 \%$ flashover voltage obtained from the tests, in $\mathrm{kV}$; $h_{1}$ is the metal to metal dry arc distance of the composite insulator, in mm. According to Equation (4), $E_{50 \%}$ of the ice-covered CI/PAG is calculated in Table 10 based on the corresponding flashover test results from Tables 3 and 4 .

Table 10. Flashover voltage gradients $E_{50 \%}$ of ice-covered CI/PAG (flashover on insulator).

\begin{tabular}{|c|c|c|c|c|}
\hline Sample & $h(\mathbf{m m})$ & $d(\mathrm{~mm})$ & $S D D / N S D D\left(\mathrm{mg} / \mathrm{cm}^{2}\right)$ & $E_{\mathrm{g}}(\mathrm{kV} / \mathrm{mm})$ \\
\hline \multirow{8}{*}{ A } & \multirow{4}{*}{80} & \multirow{2}{*}{10} & $0.05 / 0.30$ & 0.215 \\
\hline & & & $0.08 / 0.48$ & 0.187 \\
\hline & & \multirow{2}{*}{20} & $0.05 / 0.30$ & I \\
\hline & & & $0.08 / 0.48$ & 0.155 \\
\hline & \multirow{4}{*}{100} & \multirow{2}{*}{10} & $0.05 / 0.30$ & 0.210 \\
\hline & & & $0.08 / 0.48$ & 0.191 \\
\hline & & \multirow{2}{*}{20} & $0.05 / 0.30$ & 0.175 \\
\hline & & & $0.08 / 0.48$ & 0.159 \\
\hline \multirow{8}{*}{ B } & \multirow{4}{*}{80} & \multirow{2}{*}{10} & $0.05 / 0.30$ & 0.140 \\
\hline & & & $0.08 / 0.48$ & 0.128 \\
\hline & & \multirow{2}{*}{20} & $0.05 / 0.30$ & 1 \\
\hline & & & $0.08 / 0.48$ & 0.100 \\
\hline & \multirow{4}{*}{100} & \multirow{2}{*}{10} & $0.05 / 0.30$ & 0.138 \\
\hline & & & $0.08 / 0.48$ & 0.126 \\
\hline & & \multirow{2}{*}{20} & $0.05 / 0.30$ & 0.117 \\
\hline & & & $0.08 / 0.48$ & 0.104 \\
\hline
\end{tabular}

Based on Table 10, the following can be concluded:

(1) Under the condition of flashover on insulators, the $E_{50 \%}$ is mainly determined by the ice thickness $d$ and contamination severity SDD. It is free from the effect of the air gap distance $h$. Take $d$ of $10 \mathrm{~mm}$ as an example, when $S D D=0.05 \mathrm{mg} / \mathrm{cm}^{2}, h=80 \mathrm{~mm}$ or $h=100 \mathrm{~mm}, E_{50 \%}$ was 0.215 or $0.210 \mathrm{kV} / \mathrm{mm}$ respectively.

(2) The $S D D$ affects the $E_{50 \%}$ under the same ice thickness condition. For Sample A, take $d$ of $10 \mathrm{~mm}$ as an example. In the case of $S D D=0.05 \mathrm{mg} / \mathrm{cm}^{2}$ and $S D D=0.08 \mathrm{mg} / \mathrm{cm}^{2}$, the average value of $E_{50 \%}$ was 0.213 and $0.189 \mathrm{kV} / \mathrm{mm}$ respectively, the average $E_{50 \%}$ of the latter was $11.3 \%$ less than that of the former; for Sample B, take $d$ of $10 \mathrm{~mm}$ as an example, in the case of $S D D=0.05 \mathrm{mg} / \mathrm{cm}^{2}$ 
and $S D D=0.08 \mathrm{mg} / \mathrm{cm}^{2}$, the average value of $E_{50 \%}$ was 0.139 and $0.127 \mathrm{kV} / \mathrm{mm}$ respectively, with a decrease of $8.6 \%$.

(3) $E_{50 \%}$ of Sample B is more influenced by ice thickness than that of Sample A. For Sample A, in the case of $S D D=0.08 \mathrm{mg} / \mathrm{cm}^{2}, E_{50 \%}$ dropped by $17.2 \%$ with the increase of $d$ from 10 to $20 \mathrm{~mm}$; for Sample B, $E_{50 \%}$ dropped by $19.7 \%$ with the increase of $d$ from 10 to $20 \mathrm{~mm}$.

(4) $E_{50 \%}$ of Sample B is significantly lower than that of Sample A under the same conditions, which is consistent with the results of two kinds of ordinary insulators. The withstand voltage gradient of suspension insulator is also lower than that of the tension insulator under the same condition.

\section{Conclusions}

This study presented the test results of negative DC flashover performance of ice-covered CI/PAG under the conditions of various air gap distances, ice thicknesses, pollution severities, and atmospheric pressures in the artificial climate chamber. Based on the results, the following conclusions can be drawn:

(1) The distance of parallel air gap affects the discharge path of ice-covered CI/PAGs. When the air gap distance is relatively small, such as $h$ of no more than $60 \mathrm{~mm}$, the breakdown happens in the parallel gap and $U_{50 \%}$ increases with the increasing air gap distance. Even if the parallel air gap distance is relatively large and the flashover happens on insulator surfaces, due to the influences of metal fittings, the negative DC flashover voltage $U_{50 \%}$ of iced CI/PAG is lower than that of insulators without the parallel gap under the same conditions. For Sample A, the difference was from 3\% to $5.7 \%$, and for Sample B that was from $4.2 \%$ to $11.5 \%$.

(2) $U_{50 \%}$ decreases with an increase of $d$. When $h$ is relatively small and the breakdown happens in the parallel air gap: for Sample A, when $d$ was increased from 10 to $20 \mathrm{~mm}$, the average value of $U_{50 \%}$ had a decrease range from $19 \%$ to $21 \%$; for Sample B when $d$ was increased from 10 to $20 \mathrm{~mm}$, the average value of $U_{50 \%}$ had a decrease range from $42 \%$ to $52 \%$. When the $h$ is relatively large (more than $60 \mathrm{~mm}$ ), the flashover occurs on iced insulator surface and the influence of $d$ on $U_{50 \%}$ is consistent with the pattern for ordinary ice-covered insulators.

(3) Pre-pollution $S D D$ only affects $U_{50 \%}$ when the flashover happens on iced insulator surface and its influences are consistent with those on the ordinary ice-covered insulators.

(4) The $U_{50 \%}$ of two discharge paths both decline with a decrease of air pressure. $U_{50 \%}$ and the ratio of air pressure $\left(P / P_{0}\right)$ are in a power function relationship with a positive characteristic exponent. Characteristic exponent $n$ is related to the discharge path. The $n$ of air gap breakdown is larger than that of flashover on insulators. It means that the air pressure has a bigger influence on $U_{50 \%}$ of air gap breakdown than that of flashover on insulators.

\section{Acknowledgments}

The authors would like to thank the financial supports provided by the National Natural Science Foundation of China (No. 51107152), the Funds for Innovative Research Groups of China (No. 51321063), and the Foundation of National Excellent Doctoral Dissertation of PR China (FANEDD) (No. 201240), and the Fundamental Research Funds for the Central Universities (No. CDJZR12150014). 


\section{Author Contributions}

Jianlin $\mathrm{Hu}$ carried out the experiments, analyzed the test results, and wrote this paper. Xingliang Jiang gave input to the analysis of test results. Fanghui Yin checked the language and revise the contents of this manuscript. Zhijin Zhang organized the experimental setup and measurements.

\section{Conflicts of Interest}

The authors declare no conflict of interest.

\section{References}

1. Farzaneh, M.; Kiernicki, J. Flashover problems caused by ice build-up on insulators. IEEE Electr. Insul. Mag. 1995, 11, 5-17.

2. Farzaneh, M.; Savadjiev, K. Statistical analysis of field data for precipitation icing accretion on overhead power lines. IEEE Trans. Power Deliv. 2005, 20, 1080-1087.

3. Farzaneh, M. Atmospheric Icing of Power Networks; Springer: New York, NY, USA, 2008; pp. 1-4, 236-252, 271-278, 327-341.

4. Sklenicka, V.; Vokalek, J. Insulators in icing conditions: Selection and measures for reliability increasing. In Proceedings of the 7th International Workshop on Atmospheric Icing of Structures, Chicoutimi, QC, Canada, 3-7 June 1996; pp. 72-76.

5. Kannus, K.; Lahti, K. Electrical behaviour of high voltage insulator strings under rime ice. In Proceedings of the 9th International Workshop on Atmospheric Icing of Structures, Chester, UK, 5-8 June 2000; p. 8.

6. Fujimura, T.; Natio, K.; Hasegawa, Y.; Kawaguchi, T. Performance of insulators covered with snow or ice. IEEE Trans. Power Appar. Syst. 1979, PAS-98, 1621-1631.

7. Matsuda, H.; Komuro, H.; Takasu, K. Withstand voltage characteristics of insulator strings covered with snow or ice. IEEE Trans. Power Deliv. 1991, 6, 1243-1250.

8. China State Electricity Regulatory Commission. Annual Report on Electricity Regulation. 2008. Available online: http://www.chinapower.com.cn/article/1155/art1155234.asp (accessed on 14 March 2015).

9. Fu, C.; Rao, H.; Li, X.L. Development and application of DC deicer. Autom. Electr. Power Syst. 2009, 33, 53-56.

10. Tan, Y.J.; Lu, J.Z.; Fang, Z.; Li, B.; Zhang, H.X. Study of mobile DC de-icing equipment based on uncontrolled rectification. Cent. China Electr. Power 2011, 24, 31-34.

11. Wang, J.J.; Fu, C.; Chen, Y.P.; Rao, H.; Xu, S.K.; Yu, T.; Li, L.C. Research and application of DC deicing technology in China Southern power grid. IEEE Trans. Power Deliv. 2012, 27, 1234-1242.

12. Fu, C.; Xu, S.K.; Rao, H.; Li, X.L.; Chen, Y.P.; Li, L.C. Design and application of DC deicer for AC transmission system. High Volt. Eng. 2013, 39, 705-711.

13. Farzaneh, M.; Drapeau, J.F. AC flashover performance of insulators covered with artificial ice. IEEE Trans. Power Del. 1995, 10, 1311-1321. 
14. Wu, D.; Halsan, K.A.; Fikke, S.M. Artificial ice tests for long insulator strings. In Proceedings of the 7th International Workshop Atmospheric Icing of Structures, Chicoutimi, QC, Canada, 3-7 June 1996; pp. 67-71.

15. CIGRE TF 3304 09. Influence of Ice and Snow on the Flashover Performance of Outdoor Insulators-Part I: Effects of Ice; Electra: London, UK, 1999; No. 187.

16. CIGRE TF 3304 09. Influence of Ice and Snow on the Flashover Performance of Outdoor Insulators-Part II: Effects of Snow; Electra: London, UK, 2000, No. 188.

17. Farzaneh, M. Effect of ice thickness and voltage polarity on the flashover voltage of ice-covered high voltage insulators. In Proceedings of the 7th International Symposium on High Voltage Engineering, Dresden, Germany, 28-30 August 1991; pp. 203-206.

18. Hu, J.L.; Sun, C.X.; Jiang, X.L.; Zhang, Z.J.; Shu, L.C. Flashover performance of pre-contaminated and ice-covered composite insulators to be used in $1000 \mathrm{kV}$ UHV AC transmission lines. IEEE Trans. Dielectr. Electr. Insul. 2007, 14, 1347-1356.

19. Hu, J.L.; Sun, C.X.; Jiang, X.L.; Xiao, D.B.; Zhang, Z.J.; Shu, L.C. DC flashover performance of various types of ice-covered insulator strings at low air pressure. Energies 2012, 5, 1554-1576.

20. Farzaneh, M.; Chisholm, W.A. Insulators for Icing and Polluted Environments; IEEE Press: Piscataway, NJ, USA, 2009; pp. 427-431.

21. Kunhardt, E.E.; Luessen, L.H. Electrical Breakdown and Discharges in Gases (Part A: Fundamental Processes and Breakdown); Plenum Press: New York, NY, USA, 1983; pp. 207-291.

(C) 2015 by the authors; licensee MDPI, Basel, Switzerland. This article is an open access article distributed under the terms and conditions of the Creative Commons Attribution license (http://creativecommons.org/licenses/by/4.0/). 